\title{
Hypoxia-inducible factor 1 in dendritic cells is crucial for the activation of protective regulatory T cells in murine colitis
}

\author{
K Flück $^{1,2}$, G Breves ${ }^{2}$, J Fandrey ${ }^{1}$ and S Winning ${ }^{1}$
}

Dendritic cells (DCs) serve as a bridge between innate and adaptive immunity and help to maintain intestinal homeostasis. Inflammatory bowel disease (IBD) is associated with dysregulation of the mucosal immune response. The concomitant hypoxic inflammation in IBD will activate the transcription factor hypoxia-inducible factor-1 (HIF-1) to also drive gene expression in DCs. Recent studies have described a protective role for epithelial HIF-1 in mouse models of IBD. We investigated the role of HIF-1 in DC function in a dextran sodium sulfate (DSS)-induced model of murine colitis. Wild-type and dendritic cell-specific HIF-1 $\alpha$ knockout mice were treated with $3 \%$ DSS for 7 days. Knockout of HIF-1 $\alpha$ in DCs led to a significantly larger loss of body weight in mice with DSS-induced colitis than in control mice. Knockout mice exhibited more severe intestinal inflammation with increased levels of proinflammatory cytokines and enhanced production of mucin. Induction of regulatory T cells (Tregs) was impaired, and the number of forkhead box P3 (Foxp3) Tregs was diminished by dendritic HIF- $1 \alpha$ knockout. Our findings demonstrate that in DCs HIF-1 $\alpha$ is necessary for the induction of sufficient numbers of Tregs to control intestinal inflammation.

\section{INTRODUCTION}

The intestinal immune system must not only protect against infection by initiating defensive responses against pathogens, but also maintain tolerance to self-antigens, food, and commensal microflora. ${ }^{1}$ Mucosal dendritic cells (DCs) are fundamental in balancing this process. Immature DCs are present in peripheral tissues and are activated by taking up antigens in the intestine, after which they mature and migrate to the draining lymph nodes. ${ }^{2}$ Several subsets of DCs are found in the intestine. ${ }^{3}$ Depending on their cell-surface receptor expression and their cytokine profile, DCs can induce a proinflammatory $\mathrm{T}$ helper type 1 (Th1) or type 17 (Th17) or a humoral Th2 immune response. A specialized function of intestinal DCs is the induction of regulatory $\mathrm{T}$ cells (Tregs). ${ }^{4}$

Nearly every chronically inflamed tissue is characterized by low oxygen availability (hypoxia) because of vascular dysfunction and increased consumption of oxygen by infiltrating leukocytes, especially neutrophils. ${ }^{5,6}$ With respect to inflammatory bowel disease (IBD), hypoxia is likely to be of particular importance because the lumen of the gut is almost anoxic. Inflammatory impairment of the intestinal barrier allows anoxia to spread to formerly normoxic tissue that must now adapt to this condition. The hypoxia-inducible factor-1 (HIF-1) complex is a key transcription factor for cellular adaption to low oxygen tension. ${ }^{7}$ HIF-1 is a heterodimer formed by two subunits: HIF- $1 \alpha$ and HIF- $1 \beta$. Under normoxic conditions, hydroxylation of the HIF- $1 \alpha$ subunit by specific prolyl hydroxylases leads to ubiquitin-proteasome-dependent degradation. Under hypoxic conditions, however, prolyl hydroxylase activity is inhibited; thus, HIF- $1 \alpha$ can translocate into the nucleus, dimerize with HIF-1 $\beta$, and bind to hypoxia-responsive elements of HIF-1 target genes.

Several studies have addressed the function of HIF- $1 \alpha$ in intestinal epithelial cells. Karhausen $e t$ al. ${ }^{8}$ showed that loss of epithelial HIF- $1 \alpha$ led to severe intestinal inflammation, whereas an increase in epithelial HIF protein was protective. Xue et al. ${ }^{9}$ recently reported that activation of HIF- $1 \alpha$ in intestinal epithelial cells did not increase intestinal tumorigenesis. Reduction of epithelial cell apoptosis in murine colitis by

${ }^{1}$ Institut für Physiologie, Universität Duisburg-Essen, Essen, Germany and ${ }^{2}$ Physiologisches Institut, Tierärztliche Hochschule Hannover, Hannover, Germany. Correspondence: J Fandrey (joachim.fandrey@uni-due.de) 

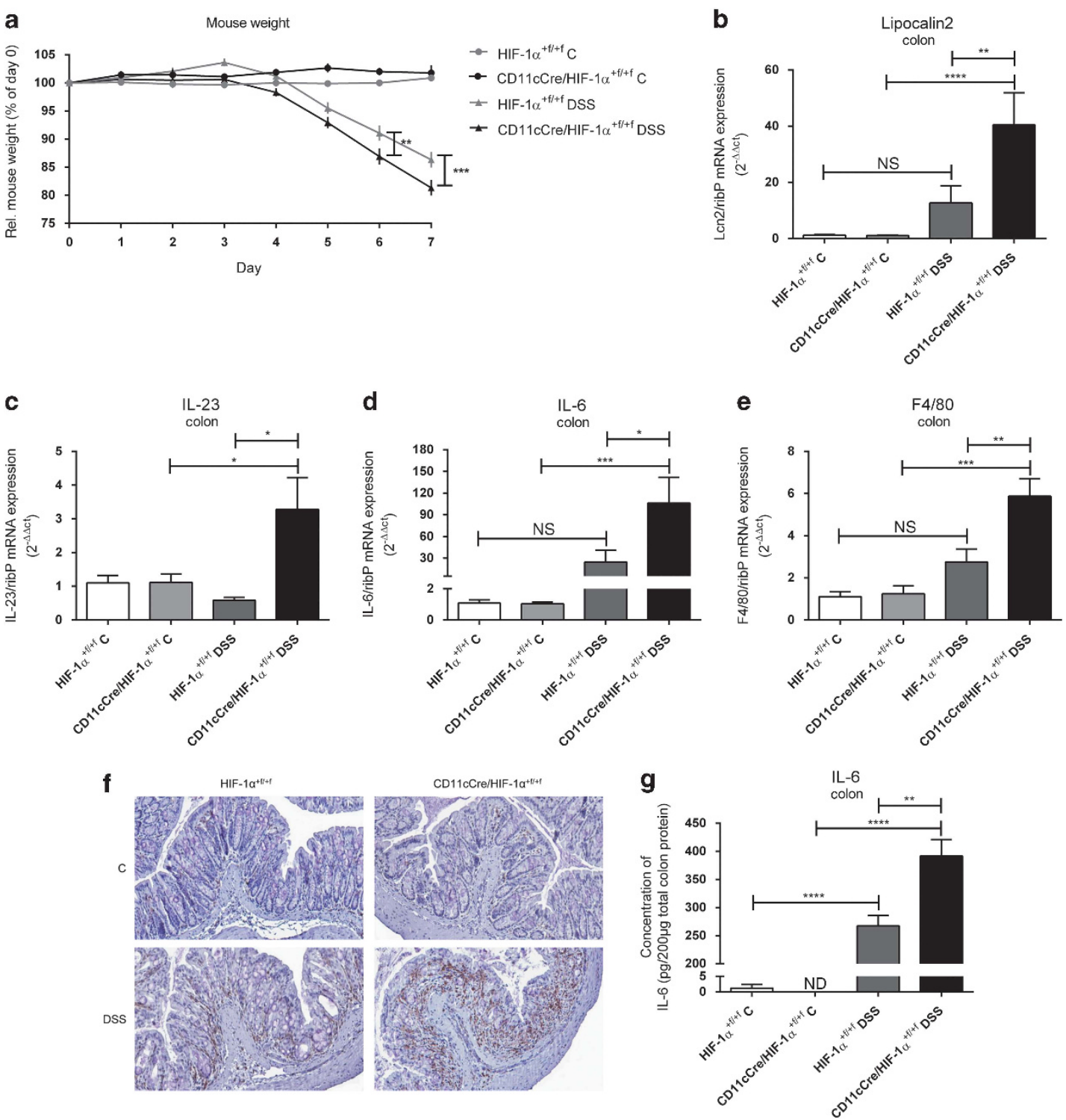

Figure 1 Dendritic cell-specific knockout of hypoxia-inducible factor-1 $\alpha$ (HIF-1 $\alpha$ ) causes more severe inflammation in dextran sodium sulfate (DSS) colitis. Colitis was induced in mice by $3 \%$ DSS in the drinking water for 7 days. (a) DSS-induced weight loss was higher in $\mathrm{CD} 11 \mathrm{cCre} / \mathrm{HIF}-1 \alpha^{+\mathrm{f} /+f}$ mice than in HIF-1 $\alpha^{+\mathrm{f} / \mathrm{f}}$ mice, with significant differences at days 6 and 7 . Control mice receiving drinking water without DSS maintained weight. $N=9-14$ per control group; $n=15-17$ per DSS group. Colonic mRNA expression of (b) lipocalin2, (c) interleukin (IL)-23, (d) IL-6, and (e) F4/80 expression after DSS treatment was significantly higher in CD $11 \mathrm{cCre} / \mathrm{HIF}-1 \alpha^{+\mathrm{f} /+\mathrm{f}}$ mice than in all other types of mice studied. (f) Sections $(4 \mu \mathrm{m})$ of colon tissue were 3,3'diaminobenzidine (DAB) stained for F4/80 (brown) and counterstained with hematoxylin (blue). After treatment with DSS, the amount of F4/80-positive cells was higher in CD11cCre/HIF-1 $\alpha^{+f /+f}$ mice than in HIF-1 $\alpha^{+f /+f}$ mice. (g) Enzyme-linked immunosorbent assay (ELISA) showed significantly higher concentrations of IL-6 in colon homogenates from DSS-treated CD11cCre/HIF- $1 \alpha^{+f /+f}$ mice than in all other groups of mice studied. $N=5-7$ per group. ${ }^{\star} P<0.05 ;{ }^{* *} P<0.01 ;{ }^{* *} P<0.001 ;{ }^{* * \star} P<0.0001$. C, control; ND, not detected; NS, not significant.

inhibition of HIF-1 degradation by the hydroxylase inhibitor dimethyloxalylglycine underscores the importance of HIF-1 in the intestinal epithelium. ${ }^{10}$ Frede et al. ${ }^{11}$ found that HIF-1 regulates inflammation and showed that lipopolysaccharide (LPS) and inflammatory cytokines lead to HIF- $1 \alpha$ accumulation. Very recent studies also demonstrated that HIF- $1 \alpha$ plays a crucial role in regulatory $\mathrm{T}$ cells and DCs. Clambey et al. ${ }^{12}$ reported a connection between HIF- $1 \alpha$ levels and the number of Tregs, as well as the expression of forkhead box P3 (Foxp3). The in vitro studies by Wobben et al. ${ }^{13}$ showed that HIF- $1 \alpha$ protein in DCs is needed for adequate production of interferon (IFN) type I and for activation of cytotoxic T cells.

Our study was designed to elucidate the effect of transcription factor HIF-1 on DCs in an experimental model of colitis by using mice with HIF- $1 \alpha$ protein knockout in CD11c-expressing cells. HIF- $1 \alpha^{+\mathrm{f} / \mathrm{f}}$ (wild-type) mice and CD11cCre/HIF-1 $\alpha^{+\mathrm{f} / \mathrm{f}}$ (knockout) mice were treated with dextran sodium sulfate (DSS) to induce colitis and then studied with respect to the severity of inflammation and activation of their immune system. 

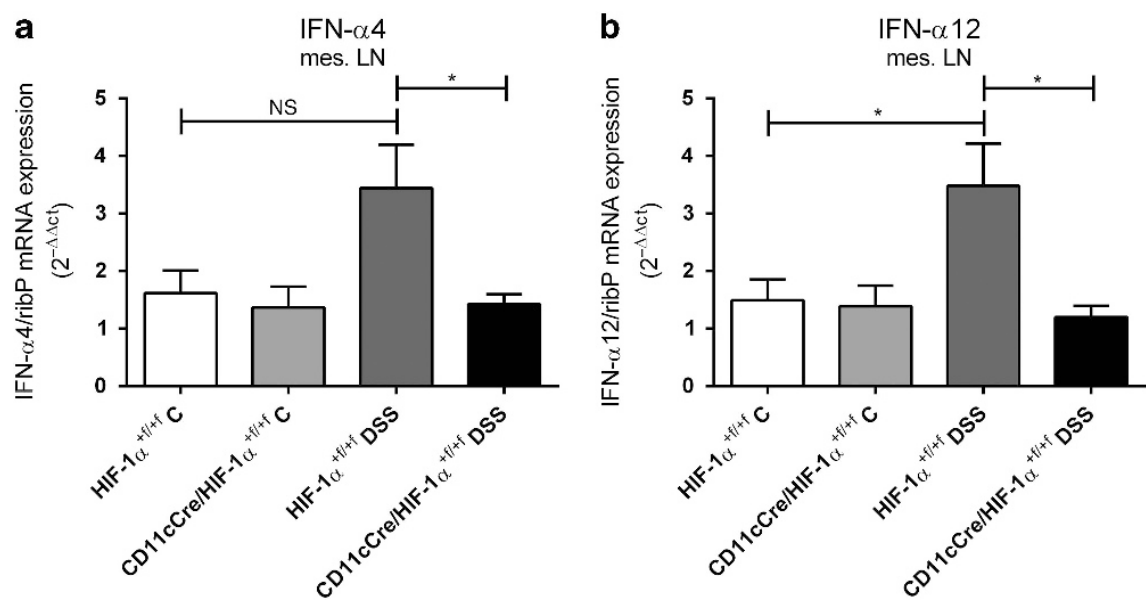

Figure 2 Hypoxia-inducible factor- $1 \alpha$ (HIF-1 $\alpha$ )-dependent induction of type I interferons (IFNs) in dextran sodium sulfate (DSS) colitis. Expression of mRNA was measured in mesenteric lymph nodes (mes. LNs). Induction of (a) IFN- $\alpha 4$ and (b) IFN- $\alpha 12$ was significantly higher in DSS-treated HIF- $1 \alpha^{+f / t}+f$ mice than in CD11cCre/HIF- $1 \alpha^{+f /+f}$ mice. $N=5-7$ per group. ${ }^{*} P<0.05$. NS, not significant.

\section{RESULTS}

DSS treatment leads to severe inflammation and profound extension of hypoxia

Initially, the efficiency of HIF- $1 \alpha$ knockout was determined in bone marrow-derived dendritic cells (BmDCs) from HIF$1 \alpha^{+\mathrm{f} /+\mathrm{f}}$ and CD11cCre/HIF- $1 \alpha^{+\mathrm{f} /+\mathrm{f}}$ mice. To quantify knockout efficiency, we performed mRNA analysis with specific HIF- $1 \alpha$ oligonucleotides binding to HIF- $1 \alpha$ complementary DNA in exon 2. DCs from CD11cCre/HIF- $1 \alpha^{+\mathrm{f} /+\mathrm{f}}$ mice showed a $90 \%$ loss of wild-type HIF-1 $\alpha$ (Supplementary Figure S1a online). CD4 ${ }^{+} \mathrm{T}$ cells and bone marrow-derived macrophages from HIF- $1 \alpha^{+\mathrm{f} /+\mathrm{f}}$ and CD11cCre/HIF- $1 \alpha^{+\mathrm{f} /+\mathrm{f}}$ mice showed equal levels of HIF- $1 \alpha$ exon 2 (Supplementary Figure S1b,c), indicating that the observed effects were specific for a dendritic knockout of HIF-1 $\alpha$.

Measuring the number of CD11 $c^{+}$cells in mesenteric lymph nodes by fluorescence-activated cell sorting analysis revealed that $\sim 2 \%$ of mesenteric lymph node cells were CD11c positive whereof $80 \%$ were vital (Supplementary Figure S1d). HIF- $1 \alpha$ knockout or DSS treatment had no effect on the number or viability of CD11c-positive cells.

Colitis was induced by treating HIF- $1 \alpha^{+\mathrm{f} /+\mathrm{f}}$ and CD11cCre/HIF- $1 \alpha^{+\mathrm{f} /+\mathrm{f}}$ mice with $3 \%$ DSS in the drinking water for 7 days. Control mice were given drinking water with $3 \%$ phosphate-buffered saline. Hematoxylin and eosin staining revealed severe inflammation caused by DSS treatment (Supplementary Figure S2a). In histological scoring we could not detect any differences between HIF-1 $\alpha^{+\mathrm{f} /+\mathrm{f}}$ and CD11cCre/HIF-1 $\alpha^{+\mathrm{f} /+\mathrm{f}}$ DSS-treated mice (Supplementary Figure S2b).

\section{Knockout of HIF-1 $\alpha$ in DCs leads to more severe inflammation in DSS-induced colitis}

We next studied the phenotype of CD11cCre/HIF- $1 \alpha^{+\mathrm{f} /+\mathrm{f}}$ mice in a DSS colitis model. Control mice maintained their weight. Both DSS-treated groups experienced progressive weight loss within 3 days. However, CD11cCre/ HIF- $1 \alpha^{+\mathrm{f} /+\mathrm{f}}$ mice lost more weight than HIF- $1 \alpha^{+\mathrm{f} /+\mathrm{f}}$ mice; the difference in weight loss was statistically significant at days 6 and $7(P<0.01$ and 0.001; Figure 1a). Characteristically, colon weight increased and colon length decreased because of DSS-induced inflammation; however, the differences between the two groups were not statistically significant (data not shown).

To investigate the impact of the dendritic HIF-1 $\alpha$ knockout on mucosal inflammation, we determined changes in mRNA expression in colon tissue after DSS exposure. We first examined the expression of lipocalin2, which is a sensitive marker of intestinal inflammation, using the DSS colitis model. ${ }^{14}$ DSS-treated CD11cCre/HIF- $1 \alpha^{+\mathrm{f} /+\mathrm{f}}$ mice exhibited significantly higher levels of lipocalin 2 than HIF- $1 \alpha^{+\mathrm{f} /+\mathrm{f}}$ mice $(P<0.01$; Figure 1b). Levels of interleukin (IL)-6 and IL-23, two proinflammatory cytokines, were significantly higher in DSS-treated CD11cCre/HIF- $1 \alpha^{+\mathrm{f} /+\mathrm{f}}$ mice than in HIF- $1 \alpha^{+\mathrm{f} /+\mathrm{f}}$ mice $(P<0.05$; Figure $\mathbf{1} \mathbf{c}, \mathbf{d})$. The expression of F4/80, a marker for macrophages, was also higher in DSStreated CD11cCre/HIF- $1 \alpha^{+\mathrm{f} /+\mathrm{f}}$ mice than in HIF- $1 \alpha^{+\mathrm{f} /+\mathrm{f}}$ mice $(P<0.01$; Figure 1e). Immunohistochemistry confirmed that DSS-treated CD11cCre/HIF- $1 \alpha^{+\mathrm{f} /+\mathrm{f}}$ mice showed higher numbers of F4/80-positive macrophages than HIF- $1 \alpha^{+\mathrm{f} /+\mathrm{f}}$ mice (Figure 1f). The DSS-induced increase in IL-6 expression in dendritic HIF- $1 \alpha$ knockout mice was confirmed at the protein level (Figure 1g). In DSS-treated CD11cCre/HIF- $1 \alpha^{+\mathrm{f} /+\mathrm{f}}$ mice we also detected significantly higher levels of mRNA expression of the inflammatory cytokine IL- $1 \beta$ and the acutephase protein serum amyloid A that correlates with the degree of intestinal inflammation. ${ }^{15}$ In DSS-treated mice, expression of total tissue HIF- $1 \alpha$ mRNA was increased that is known to accumulate during inflammation ${ }^{11}$ (Supplementary Figure S3a-c). Taken together, these findings demonstrate that DSSinduced inflammation is more severe in dendritic HIF- $1 \alpha$ knockout mice. 


\section{In vivo induction of type I IFNs is HIF-1 $\alpha$ dependent}

We had previously reported that the secretion of type I IFNs by DCs is HIF-1 dependent in vitro. ${ }^{13}$ To corroborate this finding in vivo, we analyzed mesenteric lymph nodes from HIF- $1 \alpha^{+\mathrm{f} /+\mathrm{f}}$ and CD11cCre/HIF- $1 \alpha^{+\mathrm{f} /+\mathrm{f}}$ control and DSS-treated mice for mRNA expression of IFN- $\alpha 4$ and IFN- $\alpha 12$. The induction of IFN- $\alpha 4$ (Figure 2a) and IFN- $\alpha 12$ (Figure $2 \mathbf{b}$ ) by DSS was significantly higher in HIF- $1 \alpha^{+\mathrm{f} /+\mathrm{f}}$ mice and absent in CD11cCre/HIF- $1 \alpha^{+\mathrm{f} /+\mathrm{f}}$ mice, confirming the HIF-1 $\alpha$ dependency of dendritic type I IFN production in vivo.

\section{Induction of IL-10 and TSLPR by LPS in BmDCs and induction of TSLPR in DSS-induced colitis are HIF-1 $\alpha$ dependent}

IL-10 is an anti-inflammatory cytokine secreted by DCs; it influences the phenotypes of DCs and T cells. ${ }^{16}$ To determine whether this anti-inflammatory response is affected by HIF- $1 \alpha$ knockout, BmDCs were isolated from HIF- $1 \alpha^{+\mathrm{f} /+\mathrm{f}}$ and $\mathrm{CD} 11 \mathrm{cCre} / \mathrm{HIF}-1 \alpha^{+\mathrm{f} / \mathrm{f}}$ mice, cultivated for 8 days under normoxic conditions, and then stimulated with $1 \mu \mathrm{g}$ LPS for $6 \mathrm{~h}$. IL-10 mRNA expression and protein levels were significantly higher in LPS-stimulated HIF- $1 \alpha^{+\mathrm{f} /+\mathrm{f}}$ cells than in cells from CD11cCre/HIF- $1 \alpha^{+\mathrm{f} / \mathrm{f}}$ mice $(P<0.0001$; Figure 3a,b). To better imitate the in vivo situation of mucosal DCs, BmDCs were cultivated under hypoxic conditions $\left(3 \% \mathrm{O}_{2}\right)$ for 8 days. Again, IL-10 induction by LPS was HIF-1 $\alpha$ dependent (Figure 3c). In vivo, mRNA expression of IL-10 in colon tissue showed a slight, but not significant, increase in DSS-treated HIF- $1 \alpha^{+\mathrm{f} /+\mathrm{f}}$ and CD11cCre/HIF-1 $\alpha^{+\mathrm{f} /+\mathrm{f}}$ mice (Figure 3d).

Because mucosal DCs are always influenced by intestinal epithelial cells (IECs), we looked for expression of thymic stromal lymphopoietin receptor (TSLPR) by DCs. The ligand TSLP is released by IECs and induces the production of noninflammatory DCs. ${ }^{17}$ BmDCs exhibited expression of TSLPR in vitro. Hypoxia-cultivated BmDCs from HIF$1 \alpha^{+\mathrm{f} / \mathrm{f}}$ mice exhibited a significantly larger increase of TSLPR production by LPS stimulation than did BmDCs from CD11cCre/HIF- $1 \alpha^{+\mathrm{f} /+\mathrm{f}}$ mice $(P<0.01$; Figure $3 \mathbf{e})$. This finding was confirmed in vivo as the induction of TSLPR in colon tissue from DSS-treated HIF- $1 \alpha^{+\mathrm{f} /+\mathrm{f}}$ mice was significantly higher than that in colon tissue from DSS-treated CD11cCre/HIF- $1 \alpha^{+\mathrm{f} /+\mathrm{f}}$ mice $(P<0.01$; Figure 3f). In DSS colitis, protein levels of TSLP showed a slight decrease, probably because of the destruction of a large number of IECs (Figure 3g). However, there were no significant differences in the production of TSLP by IECs in the wild-type group and the knockout group. Taken together, these findings indicate that HIF- $1 \alpha$ significantly influences the production of antiinflammatory IL-10 and TSLPR by DCs.

Induction of Treg-activating and gut-homing molecules in mesenteric lymph nodes depends on HIF-1 $\alpha$ expression in DCs in DSS-induced colitis

Mucosal DCs migrate into the mesenteric lymph nodes, where they present antigens to $\mathrm{T}$ cells. DCs can induce a proinflammatory Th1 and Th17 response, but certain mucosal DCs can also promote the differentiation of Tregs to limit inflammation. $^{18}$ To determine whether dendritic HIF- $1 \alpha$ knockout affects the induction of Tregs, we isolated mesenteric lymph nodes and measured mRNA expression of Tregactivating molecules. The levels of IL-10 and transforming growth factor- $\beta$ were significantly higher in DSS-treated HIF$1 \alpha^{+\mathrm{f} /+\mathrm{f}}$ mice than in CD11cCre/HIF- $1 \alpha^{+\mathrm{f} /+\mathrm{f}}$ mice $(P<0.05$; Figure 4a,b).

The induction of Tregs is also dependent on retinoic acid (RA). ${ }^{19}$ The activity of aldehyde dehydrogenase-1a2 (Aldh1a2), which is necessary for catalyzing retinal to RA, was significantly higher in DSS-treated HIF- $1 \alpha^{+\mathrm{f} /+\mathrm{f}}$ mice than in DSS-treated $\mathrm{CD} 11 \mathrm{cCre} / \mathrm{HIF}-1 \alpha^{+\mathrm{f} / \mathrm{f}}$ mice $(P<0.05$; Figure $4 \mathrm{c})$. Furthermore, the levels of RA receptor- $\alpha$, a ligand-inducible transcription factor ${ }^{20}$ expressed by Tregs, were significantly higher in DSS-treated HIF- $1 \alpha^{+\mathrm{f} /+\mathrm{f}}$ mice than in DSS-treated CD11cCre/HIF- $1 \alpha^{+\mathrm{f} /+\mathrm{f}}$ mice $(P<0.0001$; Figure 4d).

The gut-homing T-cell markers CC chemokine receptor 9 (CCR9) and $\alpha_{4} \beta_{7}$ integrin are dependent on activation by DCs and RA. ${ }^{21}$ Therefore, we investigated the effect of dendritic HIF-1 $\alpha$ knockout on these markers in our DSS colitis model. DSS treatment significantly increased the induction of $\alpha_{4}$ integrin in lymph nodes from wild-type and knockout mice $(P<0.01$; Supplementary Figure S4). In contrast, the expression of CCR9 and $\beta_{7}$ integrin was significantly higher in DSS-treated HIF- $1 \alpha^{+\mathrm{f} /+\mathrm{f}}$ mice than in $\mathrm{CD} 11 \mathrm{cCre} / \mathrm{HIF}-1 \alpha^{+\mathrm{f} / \mathrm{f}}$ mice $(P<0.001-0.0001$; Figure $4 \mathbf{e}, \mathbf{f})$. Taken together, these findings indicate that the loss of dendritic HIF-1 $\alpha$ leads to impaired induction of Tregs in mesenteric lymph nodes and to diminished expression of T-cell gut-homing markers.

\section{Increased numbers of $\mathrm{T}$ cells and Tregs in mesenteric lymph nodes are dependent on HIF-1 $\alpha$ expression in DCs in DSS-induced colitis}

To determine whether the dendritic HIF- $1 \alpha$ knockout influences the number of T cells and in particular of Tregs, we first looked at the presence of $\mathrm{T}$ cells in the intestine. Immunofluorescence for CD3 demonstrated an increase of CD3-positive cells through DSS treatment in HIF- $1 \alpha^{+\mathrm{f} /+\mathrm{f}}$ and CD $11 \mathrm{cCre} / \mathrm{HIF}-1 \alpha^{+\mathrm{f} /+\mathrm{f}}$ mice (Supplementary Figure S5a,b). Immunofluorescence and mRNA analysis of Foxp3, a key transcriptional regulator of Tregs, ${ }^{22}$ also showed an enhanced number and expression of Foxp3 due to DSS treatment but no differences between HIF- $1 \alpha^{+\mathrm{f} /+\mathrm{f}}$ mice and CD11cCre/HIF- $1 \alpha^{+\mathrm{f} /+\mathrm{f}}$ mice were detected in the intestine (Supplementary Figure S5c-e).

We next measured mRNA expression of CD4 and CD8a in mesenteric lymph nodes. We found a significant increase in DSS-mediated inflammation only in HIF- $1 \alpha^{+\mathrm{f} /+\mathrm{f}}$ mice, whereas the mRNA expression of CD4 and CD8a did not change in CD11cCre/HIF-1 $\alpha^{+\mathrm{f} / \mathrm{f}}$ mice $(P<0.01-0.001$; Figure 5a,b).

Expression of Foxp3 was also measured in mesenteric lymph nodes. DSS-treated HIF- $1 \alpha^{+\mathrm{f} /+\mathrm{f}}$ mice exhibited a significantly larger induction of Foxp3 mRNA than CD11cCre/HIF- $1 \alpha^{+\mathrm{f} /+\mathrm{f}}$ mice $(P<0.05$; Figure 5c). Levels 


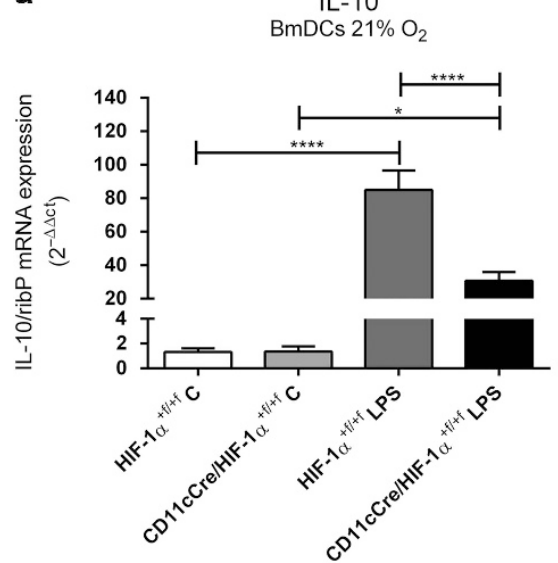

d

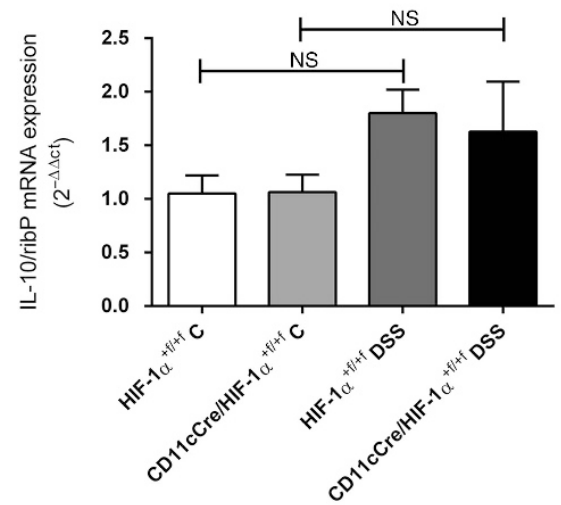

g

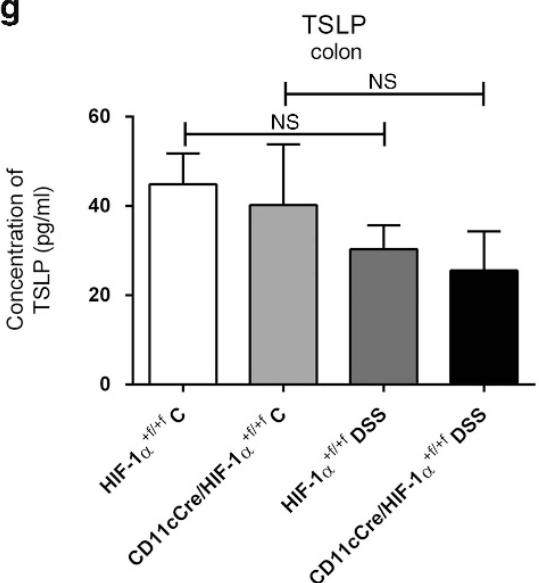

b

IL-10

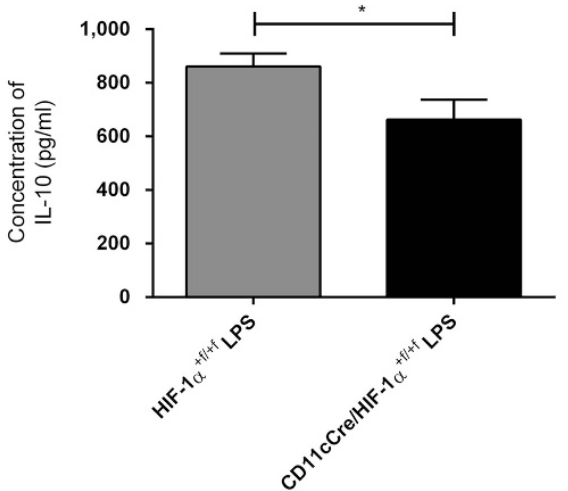

e

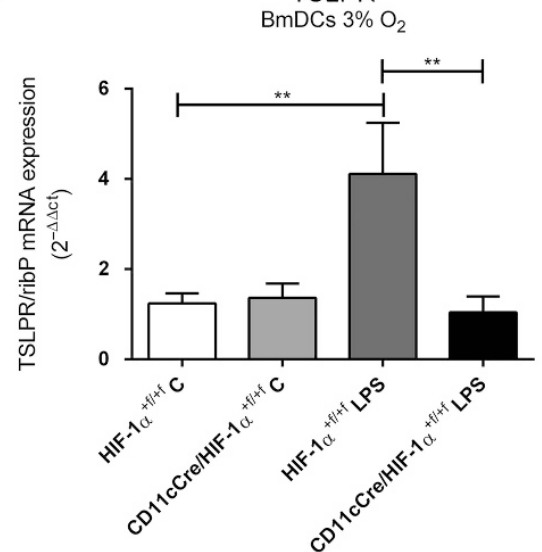

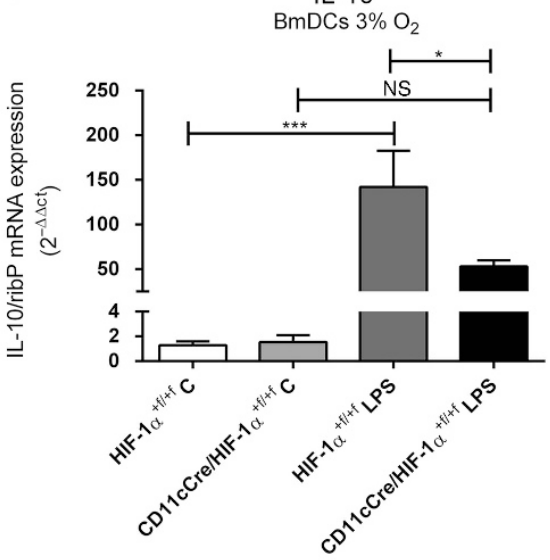

f

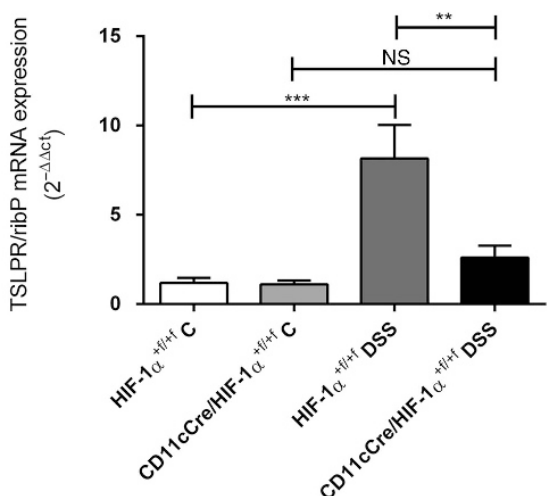

Figure 3 Inflammatory induction of interleukin-10 (IL-10) and thymic stromal lymphopoietin receptor (TSLPR) is hypoxia-inducible factor-1 $\alpha$ (HIF-1 $\alpha$ ) dependent. (a) Bone marrow-derived dendritic cells (BmDCs) were cultivated under normoxic conditions and stimulated with lipopolysaccharide (LPS). LPS-mediated IL-10 induction was significantly higher in HIF- $1 \alpha^{+f /+f}$ mice than in CD11cCre/HIF- $1 \alpha^{+f /+f}$ mice or in mice not stimulated with LPS. (b) Enzyme-linked immunosorbent assay (ELISA) showed significantly higher concentrations of IL-10 in supernatants from LPS-stimulated BmDCs from $\mathrm{HIF}-1 \alpha^{+\mathrm{f} / \mathrm{ff}}$ mice than from CD11cCre/HIF-1 $\alpha^{+\mathrm{f} /+\mathrm{f}}$ mice. (c) BmDCs were also cultivated under hypoxic conditions and stimulated with LPS. Induction of IL-10 by LPS was significantly higher in HIF- $1 \alpha^{+f /+f}$ mice than in CD 11cCre/HIF-1 $\alpha^{+f /+f}$ mice or in mice not stimulated with LPS. $N=3$; triplicate per group. (d) Expression of IL-10 by colonic mRNA was slightly higher in dextran sodium sulfate (DSS)-treated mice than in control mice, but IL-10 expression was not significantly different between HIF-1 $\alpha^{+f /+f}$ and CD11cCre/HIF-1 $\alpha^{+f /+f}$ mice. In hypoxic conditioned BmDCs, induction of $(e)$ TSLPR by LPS was significantly higher in HIF- $1 \alpha^{+f /+f}$ mice than in CD11cCre/HIF- $1 \alpha^{+f /+f}$ mice or in mice not stimulated with LPS. (f) Colonic mRNA expression of TSLPR was significantly higher in DSS-treated HIF- $1 \alpha^{+f /+f}$ mice than in all other types of mice studied. (g) ELISA for TSLP expression in colon homogenates showed a slight decrease in DSS-treated groups but no significant differences between HIF- $1 \alpha^{+f / t+f}$ and CD $11 \mathrm{cCre} / \mathrm{HIF}-1 \alpha^{+\mathrm{f} /+\mathrm{f}}$ mice. $N=5-7$ per group. ${ }^{\star} P<0.05 ;{ }^{\star \star} P<0.01 ;{ }^{\star \star \star} P<0.001 ;{ }^{\star \star \star \star} P<0.0001$. NS, not significant. 

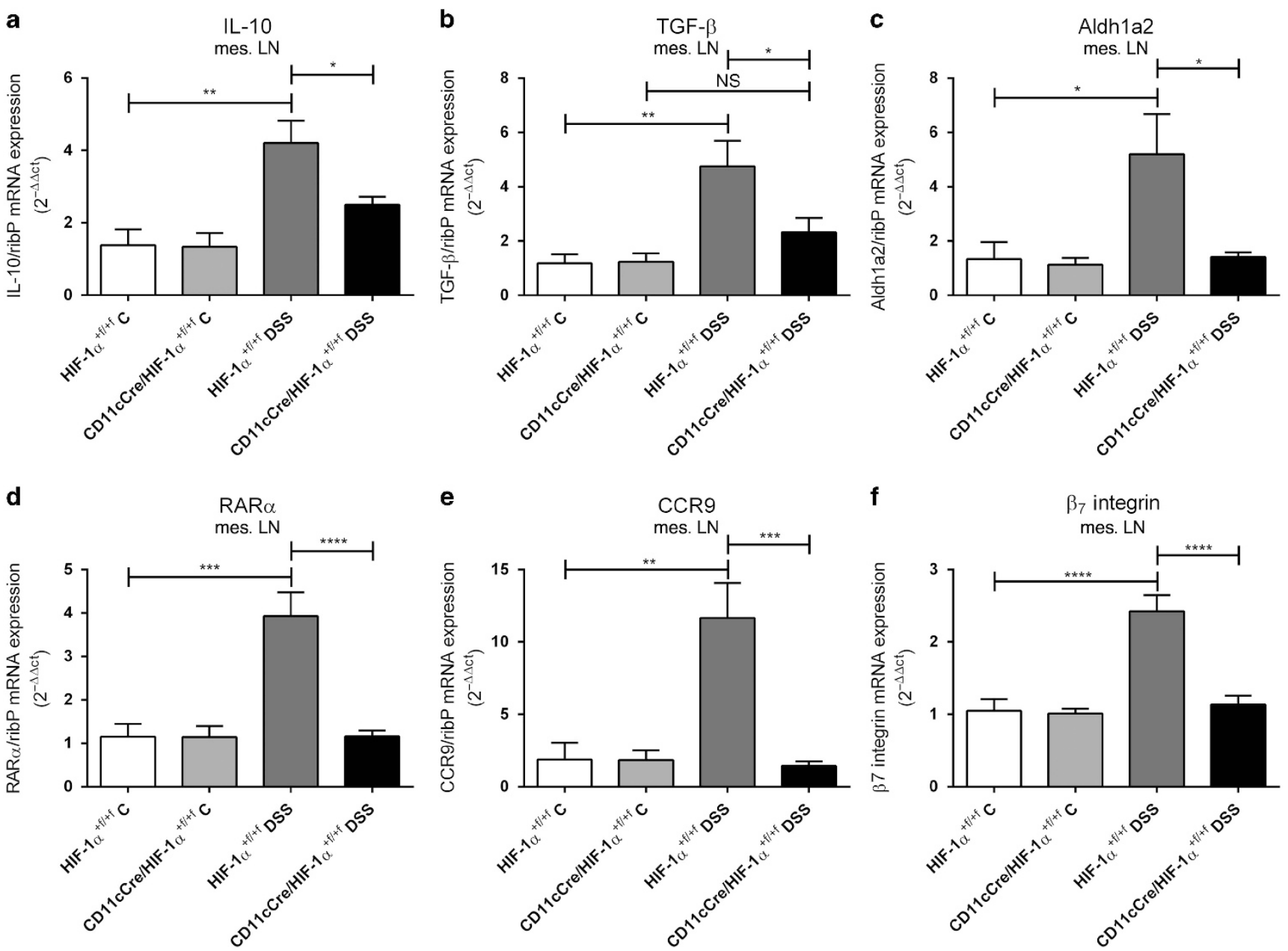

Figure 4 Activation and gut homing of regulatory T cells (Tregs) in dextran sodium sulfate (DSS) colitis require hypoxia-inducible factor- $1 \alpha$ (HIF- $1 \alpha$ ) expression in dendritic cells. Expression of mRNA was measured in mesenteric lymph nodes (mes. LNs). Levels of (a) interleukin-10 (IL-10) and (b) transforming growth factor- $\beta$ (TGF- $\beta$ ) were significantly higher in DSS-treated HIF- $1 \alpha^{+f /+f}$ mice than in DSS-treated CD $11 \mathrm{cCre} / \mathrm{HIF}-1 \alpha^{+f /+f}$ mice or in mice not treated with DSS. Expression of (c) aldehyde dehydrogenase-1a2 (Aldh1a2) and (d) retinoic acid receptor- $\alpha$ (RAR $\alpha$ ) mRNA was higher in DSS-treated HIF- $1 \alpha^{+f /+f}$ mice than in other types of mice tested. Induction of gut-homing molecules (e) CC chemokine receptor 9 (CCR9) and (f) $\beta_{7}$ integrin was higher in DSS-treated HIF- $1 \alpha^{+f /+f}$ mice than in other types of mice. $N=5-7$ per group. ${ }^{\star} P<0.05 ;{ }^{\star \star} P<0.01 ;{ }^{* \star \star} P<0.001 ;{ }^{\star * \star \star} P<0.0001$. NS, not significant.

of OX40, reported to be a surface molecule of Tregs, ${ }^{23}$ were also higher in DSS-treated HIF- $1 \alpha^{+\mathrm{f} / \mathrm{f}}$ mice than in CD11cCre/ HIF- $1 \alpha^{+\mathrm{f} /+\mathrm{f}}$ mice $(P<0.05$; Figure 5d). Enhanced numbers of Foxp3-positive Tregs were confirmed by immunofluorescence. DSS-treated HIF- $1 \alpha^{+\mathrm{f} / \mathrm{ff}}$ mice exhibited more Foxp3-positive cells (red) in mesenteric lymph nodes than did knockout mice (Figure 5e). These findings indicate that knockout of dendritic HIF-1 $\alpha$ in DSS colitis leads to lower numbers of $\mathrm{T}$ cells and Tregs in mesenteric lymph nodes.

Regarding the proliferation marker Ki-67, untreated mice showed positive cells only in the intestinal crypts. Through DSS treatment, invaded immune cells in all intestinal layers were positive for Ki-67, indicating a high proliferation rate of these cells. HIF- $1 \alpha^{+\mathrm{f} /+\mathrm{f}}$ and CD $11 \mathrm{cCre} / \mathrm{HIF}-1 \alpha^{+\mathrm{f} / \mathrm{ff}}$ mice did not differ in the amount of Ki-67-positive cells (Supplementary Figure S6).

\section{DC-specific knockout of HIF-1 $\alpha$ stimulates mucosal epithelium to increase the production of mucins in DSS-induced colitis}

Because DCs are in close contact with epithelial cells, ${ }^{24}$ we examined the influence of the DC-specific HIF- $1 \alpha$ knockout on IECs in DSS colitis. Goblet cells produce mucins and trefoil factors, thus forming a protective mucus layer that coats the gastrointestinal tract. ${ }^{25}$ Using Alcian blue, which generally stains mucopolysaccharides, we first ensured that the knockout of HIF-1 $\alpha$ in DCs did not affect mucus production under control conditions. In DSS colitis, CD11cCre/HIF- $1 \alpha^{+\mathrm{f} /+\mathrm{f}}$ mice showed enhanced and more intense staining compared with HIF- $1 \alpha^{+\mathrm{f} / \mathrm{f}}$ mice in the intestine (Supplementary Figure S7). Expression of MUC1, MUC2, and MUC3 mRNA in the colon was significantly higher in DSS-treated CD11cCre/HIF- $1 \alpha^{+\mathrm{f} / \mathrm{f}}$ mice than in DSStreated HIF- $1 \alpha^{+\mathrm{f} / \mathrm{f}}$ mice $(P<0.05-0.01$; Figure $\mathbf{6 a}-\mathbf{c})$. 
a

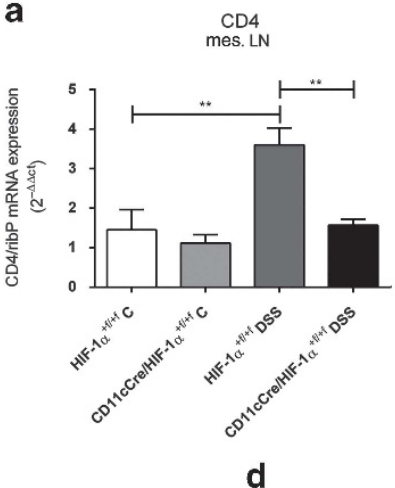

b
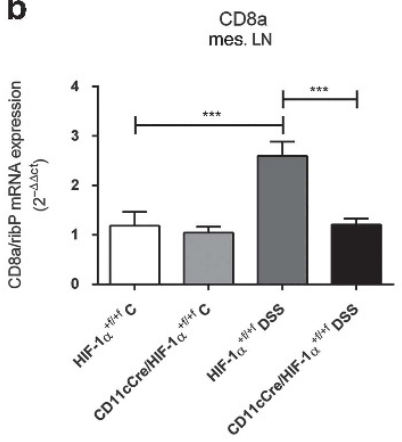

e
$H \mathrm{HF}-1 \mathrm{\alpha}^{+1+3+1}$

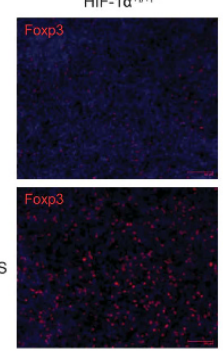

C

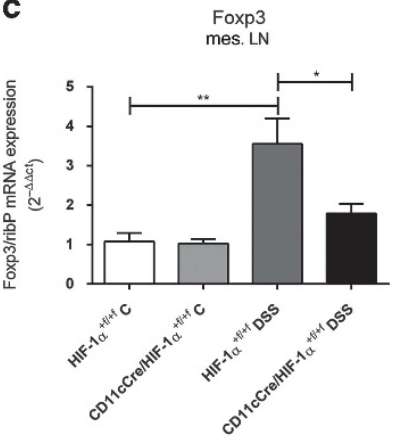

CD11cCre/HIF-1a $a^{+f i+1}$
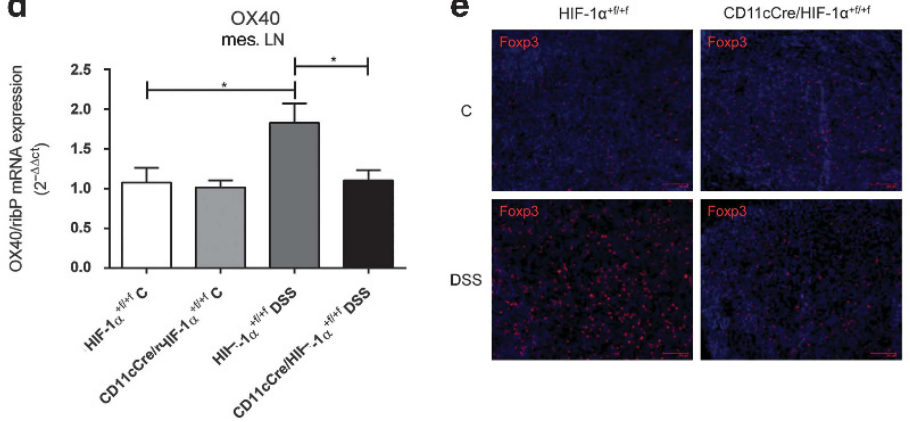

Figure 5 Increases in numbers of T cells and regulatory T cells (Tregs) in mesenteric lymph nodes (mes. LNs) depend on dendritic hypoxia-inducible factor- $1 \alpha(\mathrm{HIF}-1 \alpha)$ expression in dextran sodium sulfate (DSS) colitis. Expression of mRNA was measured in mes. LNs. (a) CD4 and (b) CD8 mRNA expression was significantly higher in DSS-treated HIF- $1 \alpha^{+f /+f}$ mice than in CD11cCre/HIF- $1 \alpha^{+f /+f}$-treated mice or in either type of mouse not treated with DSS. The expression of Treg markers (c) forkhead box P3 (Foxp3) and (d) OX40 mRNA was significantly higher in DSS-treated HIF-1 $\alpha^{+f /+f}$ mice than in DSS-treated CD11cCre/HIF-1 $\alpha^{+f /+f}$ mice or in mice not treated with DSS. (e) Sections $(4 \mu \mathrm{m})$ of mes. LNs were stained with Foxp3 (red) and 4',6diamidino-2-phenylindole (DAPI; blue). The number of Foxp3-positive cells (red) after DSS colitis was enhanced only in HIF-1 $\alpha^{+f /+f}$ mice (original magnification $\times 200$; scale bar $=50 \mu \mathrm{m}) . N=5-7$ per group. ${ }^{\star} P<0.05$; ${ }^{\star \star} P<0.01$; ${ }^{\star \star \star} P<0.001$. C, control.

Immunofluorescence studies confirmed enhanced MUC2 protein levels in CD11cCre/HIF-1 $\alpha^{+\mathrm{f} /+\mathrm{f}}$ mice compared with HIF- $1 \alpha^{+\mathrm{f} / \mathrm{f}}$ mice (Figure $6 \mathbf{d}$ ). Levels of trefoil factor 3 mRNA were significantly higher than control levels only in DSS-treated knockout mice, but not in DSS-treated wild-type mice (Supplementary Figure S8). In total, these findings demonstrate that in the DSS-induced colitis the loss of HIF- $1 \alpha$ by DCs affects the crosstalk between DCs and IECs, causing IECs to produce more mucins.

\section{DISCUSSION}

HIF plays a crucial role in the regulation of many immune cells. It is well established that in myeloid cells HIF- $1 \alpha$ promotes cell survival and migration, invasiveness, and bacterial killing. ${ }^{26,27}$ In T cells, HIF-1 controls the balance between Tregs and Th17 differentiation. ${ }^{28}$ In DCs, cell differentiation, migration, and hypoxic cell survival is regulated by HIF-1. ${ }^{29-31}$ In experimental models of colitis it has been shown that epithelial HIF-1 has an antiinflammatory and protective function through the induction of barrier protective genes. ${ }^{32}$ In addition, the use of prolyl hydroxylase inhibitors, which stabilize the HIF complex, provided beneficial effects in two different murine colitis models. ${ }^{10,33}$ Various studies have shown that not only the epithelium but also the whole intestinal tissue is exposed to hypoxia during inflammation, ${ }^{5,8}$ and it becomes increasingly relevant to consider the function of HIF in different immune cells. It has been reported that HIF-1 in T cells ameliorates DSSinduced colitis by controlling the balance of Tregs and $\mathrm{T}$ effector cells. ${ }^{34}$ Treg-intrinsic HIF- $1 \alpha$ is further required for an optimal Treg function to control colitis. ${ }^{12}$ We now focused on the role of HIF-1 $\alpha$ in DCs because they play a crucial role in regulating the immune response and are also involved in the pathogenesis of IBD. ${ }^{35}$ In the current report we show for the first time that dendritic HIF- $1 \alpha$ exerts a pivotal influence on the control of colitis. The absence of dendritic HIF-1 $\alpha$ leads to a more severe intestinal inflammation with higher body weight loss, increased levels of inflammatory cytokines, and impaired induction of Tregs (Figure 7).

Lipocalin2 is a known regulator of the gut's immune response. $^{36}$ It is a member of the lipocalin protein family and is apically secreted by epithelial cells. Chassaing et al. ${ }^{14}$ measured fecal lipocalin2 levels with enzyme-linked immunosorbent assay and reported that these levels are upregulated in murine models of colitis. When we determined colonic mRNA expression, we found elevated levels of lipocalin2 in our knockout mice in DSS-induced colitis, a finding indicating a more severe inflammation (Figure 1b). Inflammatory cytokines such as IL-6 and IL-23 are strongly involved in the pathogenesis of IBD. ${ }^{37,38}$ IL- 6 can inhibit Treg-mediated suppression in a murine model of colitis. ${ }^{39}$ It has been shown that IL-23 promotes inflammation by IL- 6 and IL-17 and drives a Th17 immune response. ${ }^{38} \mathrm{~A}$ recent study demonstrated that 
a

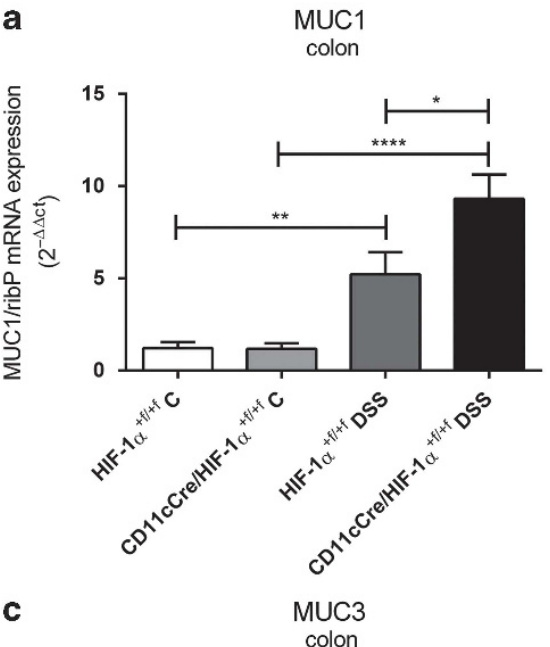

C

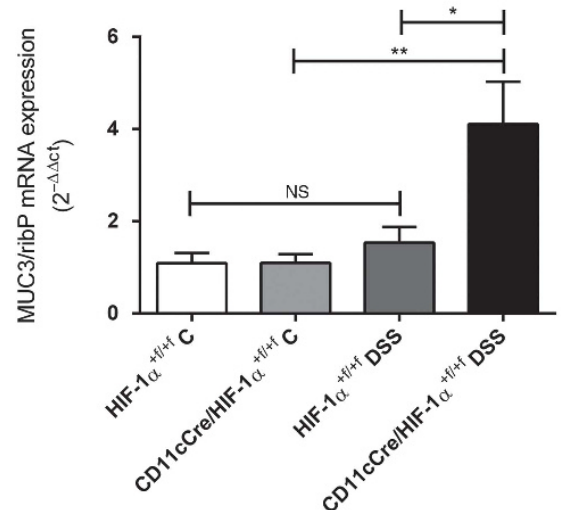

b

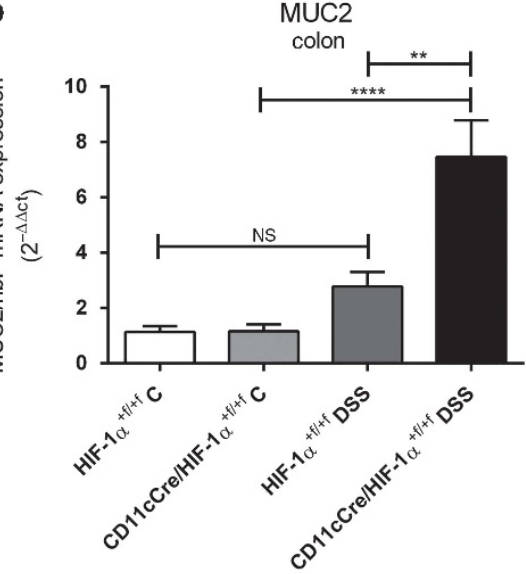

d HIF-1 $1 \alpha^{+1+1+1}$
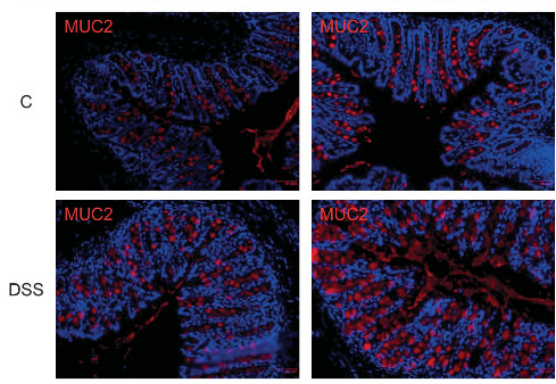

Figure 6 Dendritic cell-specific knockout of hypoxia-inducible factor-1 $\alpha$ (HIF-1 $\alpha$ ) stimulates mucosal epithelium to increased production of mucins in dextran sodium sulfate (DSS) colitis. Colonic mRNA expression of (a) MUC1, (b) MUC2, and (c) MUC3 was significantly higher in DSS-treated CD11cCre/HIF- $1 \alpha^{+f /+f}$ mice than in HIF- $1 \alpha^{+f /+f}$ DSS-treated mice or in mice not treated with DSS. (d) Sections $(4 \mu \mathrm{m})$ of colon tissue were stained with MUC2 (red) and 4',6-diamidino-2-phenylindole (DAPI; blue). After treatment with DSS, the amount of colonic MUC2 protein was higher in CD11cCre/HIF$1 \alpha^{+\mathrm{f} /+\mathrm{f}}$ mice than in HIF-1 $\alpha^{+\mathrm{f} / \mathrm{f}}$ mice (original magnification $\times 200$; scale bar $=50 \mu \mathrm{m}$ ). $N=5-7$ per group. ${ }^{\star} P<0.05 ;{ }^{* *} P<0.01 ;{ }^{* * * *} P<0.0001$. C, control; NS, not significant.

lamina propria DCs constitutively express IL-23, ${ }^{40}$ demonstrating additional influence of DCs on IBD. Herein, we found higher levels of IL- 6 and IL-23 in DSS-treated CD11cCre/HIF$1 \alpha^{+\mathrm{f} / \mathrm{ff}}$ mice than in HIF- $1 \alpha^{+\mathrm{f} /+\mathrm{f}}$ mice, indicating that HIF-1 is involved in this regulation (Figure 1c,d). Collectively, knockout of HIF-1 $\alpha$ in DCs exposed to inflammation and hypoxia caused upregulation of inflammatory mediators from both DCs and epithelial cells.

We recently reported that dendritic IFN- $\alpha$ production in vitro is HIF- $1 \alpha$ dependent. ${ }^{13}$ Herein, we now confirmed these findings in vivo, because our knockout mice exhibited less expression of IFN- $\alpha 4$ and IFN- $\alpha 12$ mRNA after DSS treatment (Figure 2a,b). Type I IFNs are known to exert protective effects in intestinal inflammation by preventing epithelial barrier dysfunction and inhibiting the inflammatory response of activated macrophages. ${ }^{41,42}$ This is in line with our present finding that $\mathrm{HIF}-1 \alpha^{+\mathrm{f} / \mathrm{ff}}$ mice exhibit fewer infiltrated macrophages than do CD11cCre/HIF- $1 \alpha^{+\mathrm{f} /+\mathrm{f}}$ mice in DSS colitis, likely because of the reduced expression of type I IFNs (Figure 2e,f).
Counterbalancing these proinflammatory signals, Tregs induced by a subset of intestinal DCs are protective in intestinal inflammation. ${ }^{43}$ Tregs are defined by the expression of Foxp3. ${ }^{22}$ We found fewer Foxp3-positive cells in our knockout mice concomitant with a more severe inflammation. The induction of Tregs is further dependent on the release of RA and transforming growth factor- $\beta$ by DCs. ${ }^{21} \mathrm{RA}$ is converted from retinal by Aldhs. Aldh1a2 is found primarily in DCs in the mesenteric lymph nodes, ${ }^{19}$ and RA resulting from its enzymatic activity can inhibit the IL-6-mediated induction of proinflammatory Th17 cells. ${ }^{44}$ DSS treatment failed to induce transforming growth factor- $\beta$, Aldh1a2, and RA receptor- $\alpha$ in our DSS-treated mice with DCs lacking HIF$1 \alpha$ (Figure $4 \mathbf{b}-\mathbf{d}$ ). HIF- $1 \alpha$-deficient DCs may secrete less RA because of the decrease in Aldh1a2 expression and cause lower expression of RA receptor- $\alpha$ that is directly induced by RA. ${ }^{20}$

Treg induction also relies on DC-secreted IL-10. ${ }^{16}$ Spontaneous colitis develops in IL-10 knockout mice after a few weeks. ${ }^{45}$ Several studies have demonstrated that HIF- $1 \alpha$ influences IL-10 production. Cai et al. ${ }^{46}$ showed that HIF-1 $\alpha$ 

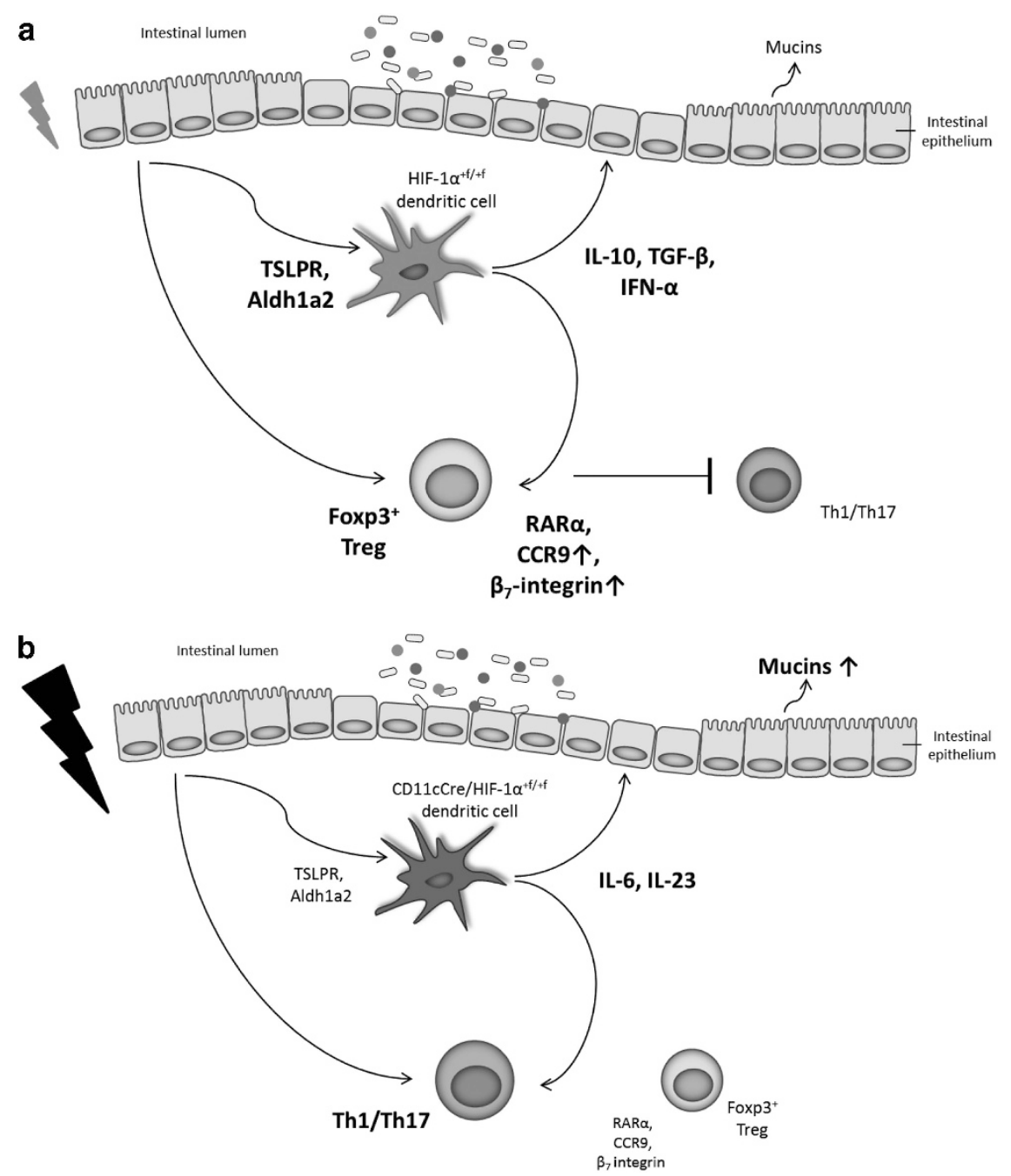

Figure 7 Hypoxia-inducible factor-1 (HIF-1) activation in dendritic cells determines the severity of colitis. (a) Dendritic cells from HIF- $1 \alpha^{+\mathrm{f} /+\mathrm{f}}$ (wild-type) mice show increased expression of thymic stromal lymphopoietin receptor (TSLPR) and develop a tolerogenic phenotype with high expression of aldehyde dehydrogenase-1a2 (Aldh1a2), interleukin-10 (IL-10), and transforming growth factor- $\beta$ (TGF- $\beta$ ) in dextran sodium sulfate (DSS)-induced colitis. This leads to intense activation of regulatory T cells (Tregs) that show high expression of RA receptor- $\alpha$ (RAR $\alpha)$ and CC chemokine receptor 9 (CCR9) and $\beta_{7}$ integrin. Proinflammatory Thelper type 1 (Th1) and type 17 (Th17) immune responses are inhibited through activated Tregs and enhanced production of IFN- $\alpha$ by HIF- $1 \alpha^{+f /+f}$ dendritic cells is protective in colitis. (b) In CD11cCre/HIF-1 $\alpha^{+f /+f}$ (knockout) mice, expression of TSLPR and Aldh1a2 is diminished and the production of IL-6 and IL-23 is enhanced, leading to a proinflammatory Th1 and Th17 immune responses. Effector lymphocytes show less expression of RAR $\alpha$ and CCR9 and $\beta_{7}$ integrin. Production of mucins by the intestinal epithelium is enhanced in CD11cCre/HIF$1 \alpha^{+f /+f}$ mice because of a more severe colitis.

activates IL-10 production in myocytes and is required for remote preconditioning of the heart. Stabilization of HIF- $1 \alpha$ by treatment with dimethyloxalylglycine increased LPS-induced expression of IL-10. ${ }^{47}$ In this study we found for the first time that dendritic loss of HIF- $1 \alpha$ directly leads to diminished levels of IL-10 in vitro (Figure 3a-c) and in the lymph nodes in vivo (Figure 4a), with a severe impact on intestinal inflammation. The fact that we could not detect significant changes in IL-10 mRNA expression in the colon (Figure 3d) may be because of the small numbers of DCs in colon tissue.

Intestinal DCs can induce the specific gut-homing markers $\alpha_{4} \beta_{7}$ integrin and CCR9 on Tregs. ${ }^{48}$ RA enhances the expression of $\alpha_{4} \beta_{7}$ integrin and CCR9. ${ }^{19}$ We found that the expression of $\beta_{7}$ integrin and CCR9 was significantly higher in
DSS-treated HIF- $1 \alpha^{+\mathrm{f} / \mathrm{f}}$ mice than in knockout mice (Figure 4e,f), a finding indicating that dendritic HIF- $1 \alpha$ is needed for adequate Treg homing. Together, our findings are conceivable with fewer Tregs in CD11cCre/HIF- $1 \alpha^{+\mathrm{f} /+\mathrm{f}}$ mice suffering from DSS colitis. This was indeed indicated by reduced CD4 but more specifically Foxp3- and OX40expressing cells (Figure 5a-d).

Of interest to us was the potential crosstalk between IECs and DCs. ${ }^{17}$ IECs release TSLP that conditions mucosal DCs to noninflammatory tolerogenic DCs. Jang et al. ${ }^{49}$ demonstrated that the expression of TSLP in keratinocytes is HIF- $1 \alpha$ dependent. We were unable to detect differences in the expression of TSLP in colon tissue probably because IECs in our model express active HIF- $1 \alpha$. However, expression of the 
TSLPR was induced by LPS only in BmDCs from HIF- $1 \alpha^{+\mathrm{f} /+\mathrm{f}}$ mice (Figure 3e). Correspondingly, in vivo only HIF- $1 \alpha^{+\mathrm{f} / \mathrm{f}}$ mice exhibited increased levels of TSLPR in DSS colitis (Figure 3f).

Furthermore, we detected a reciprocal interaction between IECs and DCs. Knockout of dendritic HIF- $1 \alpha$ leads to increased production of MUC1-3 (Figure 6a-d). Mucins are produced primarily by goblet cells and play a crucial role in mucosal protection. The expression of mucins in intestinal inflammation depends on the severity and degree of colitis. ${ }^{25}$ Van der Sluis et al. ${ }^{50}$ reported that MUC2 knockout mice develop spontaneous colitis and are more prone to DSS colitis. Furthermore, Yokoigawa et al. ${ }^{51}$ found that mucins secreted from colon cancer cells induce the production of IL-6. Other studies have demonstrated IL-6-mediated induction of MUC2 and MUC3 in colon carcinoma cells. ${ }^{52,53}$ In our DSStreated knockout mice, higher levels of IL- 6 were associated with higher levels of mucins. This association may result from a compensatory protective mechanism in the intestinal epithelium, because mucins are also involved in mucosal repair. ${ }^{54,55}$

Therapeutic strategies may be derived for models of IBD to use hydroxylase inhibitors that provided various protective effects in IBD. ${ }^{56}$ Systemically applied hydroxylase inhibitors not only affect the gut epithelium but also immune cells like neutrophils, $\mathrm{T}$ cells, and DCs. In this study we found effects on IBD by exclusively knocking out HIF-1 in DCs; thus selectively activating HIF-1 in DCs could provide a protective effect in IBD. The systemic use of hydroxylase inhibitors will in addition have potential side effect such as raising the hematocrit or supporting tumor development. ${ }^{57}$ Therefore, the concept of targeted administration of hydroxylase inhibitors to the inflamed epithelium over a short therapeutic time frame appears very appealing. ${ }^{56}$ In fact, such a therapeutic application route could also reach DCs when the barrier function of the epithelium is impaired and DCs have just entered the underlying stroma. Targeting intestinal DCs may therefore be an attractive therapeutic option in the treatment of IBD.

\section{METHODS}

Mice. C57Bl/6J mice with two loxP sites flanking exon 2 of the hif-1 $\alpha$ gene $\left(\mathrm{HIF}-1 \alpha^{+\mathrm{f} / \mathrm{f}}\right.$, purchased from The Jackson Laboratory, Bar Harbor, ME) were crossed with mice in which the integrin $\alpha \mathrm{X}$ (CD11c) promoter drives Cre recombinase expression (CD11cCre/ HIF- $1 \alpha^{+\mathrm{f} /+\mathrm{f}}$ ) to achieve a CD11c cell-specific knockout of HIF- $1 \alpha$. In these mice, exon 2 encodes for the DNA binding site of translated HIF$1 \alpha$ protein. Knockout mice exhibit significantly reduced expression of functionally active HIF- $1 \alpha$ protein in CD11c-expressing cells and also exhibit a loss of function of the HIF-1 complex. Sibling mice negative for Cre recombinase (HIF- $1 \alpha^{+\mathrm{f} /+\mathrm{f}}$ ) served as controls. All animals demonstrated physiological habitus and bred regularly. Animal experiments were performed in full accordance with the German law for animal welfare and with institutional regulations for animal breeding and handling and approved by the Landesamt für Umwelt-, Natur- und Verbraucherschutz Nordrhein-Westfalen (LANUV NRW; file reference 84-02.04.2011.A098).

DSS colitis model. Colitis was induced by treatment with DSS (MP Biomedicals, Santa Ana, CA) ${ }^{58}$ Female mice 10 to 12 weeks old were given 3\% DSS dissolved in drinking water for 7 days and body weight was recorded daily. On day 7, mice were killed by cervical dislocation, and mesenteric lymph nodes and colonic tissues were dissected.

Primary murine BmDCs. DCs were isolated from HIF- $1 \alpha^{+\mathrm{f} / \mathrm{f}}$ and CD11cCre/HIF- $1 \alpha^{+\mathrm{f} /+\mathrm{f}}$ mice as previously described. ${ }^{13}$ Cells were cultivated under normoxic $\left(\mathrm{O}_{2} / \mathrm{CO}_{2} / \mathrm{N}_{2}, 21: 5: 74 \mathrm{vol} \%\right)$ and hypoxic $\left(\mathrm{O}_{2} / \mathrm{CO}_{2} / \mathrm{N}_{2}, 3: 5: 92\right.$ vol\%) conditions. On culture day 8, DCs were incubated for $6 \mathrm{~h}$ with $1 \mu \mathrm{g} \mathrm{ml}^{-1}$ LPS (serotype 0111:B4, Sigma, Deisenhofen, Germany); total RNA was then extracted.

Cell isolation. Primary murine $\mathrm{BmDCs}$ were isolated from HIF- $1 \alpha^{+\mathrm{f} /+\mathrm{f}}$ and CD11cCre/HIF- $1 \alpha^{+\mathrm{f} /+\mathrm{f}}$ mice as previously described. ${ }^{13}$ Cells were cultivated under normoxic $\left(\mathrm{O}_{2} / \mathrm{CO}_{2} / \mathrm{N}_{2}\right.$, 21:5:74 vol\%) and hypoxic $\left(\mathrm{O}_{2} / \mathrm{CO}_{2} / \mathrm{N}_{2}, 3: 5: 92 \mathrm{vol} \%\right)$ conditions. On culture day 8 , DCs were incubated for $6 \mathrm{~h}$ with $1 \mu \mathrm{g} \mathrm{ml}^{-1}$ LPS (serotype 0111:B4, Sigma); total RNA was then extracted. Primary murine bone marrow-derived macrophages were isolated from HIF$1 \alpha^{+\mathrm{f} / \mathrm{f}}$ and CD11cCre/HIF- $1 \alpha^{+\mathrm{f} /+\mathrm{f}}$ mice as previously described. ${ }^{59}$ Cells were cultivated for 12 days under normoxic $\left(\mathrm{O}_{2} / \mathrm{CO}_{2} / \mathrm{N}_{2}, 21: 5: 74\right.$ vol\%) conditions and then stimulated under hypoxic $\left(\mathrm{O}_{2} / \mathrm{CO}_{2} / \mathrm{N}_{2}\right.$, 3:5:92 vol\%) conditions for $6 \mathrm{~h}$ before total RNA was extracted. $\mathrm{CD}^{+} \mathrm{T}$ cells were isolated from spleens from HIF- $1 \alpha^{+\mathrm{f} /+\mathrm{f}}$ and CD11cCre/HIF- $1 \alpha^{+\mathrm{f} /+\mathrm{f}}$ mice with CD4 MicroBeads (Miltenyi Biotec, Bergisch Gladbach, Germany); total RNA was directly extracted.

Flow cytometry. Cells of mesenteric lymph nodes were incubated with a fluorescently labeled antibody against CD11c (N418, BioLegend, San Diego, CA) and analyzed by fluorescence-activated cell sorting as previously described. ${ }^{13}$

RNA preparation and reverse transcriptase-PCR. RNA was isolated from BmDCs as previously described. ${ }^{13}$ Total RNA was isolated from lymph nodes and colon with the RNeasy Mini Kit (Qiagen, Hilden, Germany). Primer sequences used for quantitative PCR are listed in Supplementary Table S1 (Invitrogen, Darmstadt, Germany). Quantitative detection of IFN- $\alpha$ subtypes was performed with the QuantiTect Primer Assay (Qiagen). Real-time PCR was performed with SYBR green fluorescent dye (Eurogentec, Verviers, Belgium) on the iQ5 Real-Time PCR detection system (Bio-Rad, Munich, Germany). Amounts of complementary DNA were normalized to ribosomal protein, and expression was calculated as induction relative to respective controls with the $\Delta \mathrm{ct}$ method. ${ }^{13}$

Cytokine analysis. Levels of IL-6, IL-10, and thymic stromal lymphopoietin were detected in colon homogenates and supernatants from BmDCs according to the manufacturer's instructions (enzymelinked immunosorbent assay MAX Deluxe, BioLegend). Concentrations were expressed as $\mathrm{pg} \mathrm{g}^{-1}$ colon homogenate or $\mathrm{pg} \mathrm{ml}^{-1}$ cell culture supernatant.

Immunostaining. Sections of colon tissue were stained with hematoxylin (Merck, Darmstadt, Germany) and eosin (Sigma). Histological assessment was performed as described previously. ${ }^{60}$ F4/80 was detected using a rat anti-mouse F4/80 antibody (AbD Serotec, Kidlington, UK). Ki-67 was detected with a rabbit anti-mouse Ki-67 antibody (DCS, Hamburg, Germany). Goat-anti rat (Santa Cruz Biotechnology, Santa Cruz, TX) and goat anti-rabbit (Dako, Glostrup, Denmark) antibodies were used as secondary antibodies. For immunohistochemistry the $\mathrm{ABC}$ immunodetection (Vectastain Elite ABC Kit; Vector Laboratories, Peterborough, UK) and Diaminobenzidine as chromogen (Vector Laboratories) were used. CD3 was detected with a goat polyclonal CD3- $\varepsilon$ antibody (Santa Cruz Biotechnology). Foxp3 was detected with a rat anti-mouse Foxp3 antibody (eBioscience, San Diego, CA). MUC2 was detected with a rabbit anti-mouse MUC2 antibody (Santa Cruz Biotechnology). For immunofluorescence Alexa Fluor 488 and $568 \mathrm{~s}$ antibodies were used (Invitrogen). Alcian blue staining was performed with Alcian blue solution (Sigma). 
Statistical analysis. Data were compared by one-way analysis of variance with GraphPad Prism 6 software (GraphPad Software, La Jolla, CA); the Tukey-Kramer post hoc test was used to determine the statistical significance of the differences between the groups. Expression of DSS-treated samples was normalized to untreated controls of the same genotype. Untreated groups showed no differences in any gene expression. Values are expressed as means \pm s.e.m. for $n$ individual experiments. $P$-values 0.05 were considered significant.

SUPPLEMENTARY MATERIAL is linked to the online version of the paper at http://www.nature.com/mi

\section{ACKNOWLEDGMENTS}

We thank Flo Witte for critical reading of the manuscript and Yvonne Hüsecken and Agnes Neugebauer for technical support. We thank Boris Reizis (Columbia University Medical Center, New York, NY) for providing CD11cCre mice.

\section{DISCLOSURE}

The authors declared no conflict of interest.

c) 2016 Society for Mucosal Immunology

\section{REFERENCES}

1. Mowat, A.M. Anatomical basis of tolerance and immunity to intestinal antigens. Nat. Rev. Immunol. 3, 331-341 (2003).

2. Banchereau, J. \& Steinman, R.M. Dendritic cells and the control of immunity. Nature 392, 245-252 (1998).

3. Coombes, J.L. \& Powrie, F. Dendritic cells in intestinal immune regulation. Nat. Rev. Immunol. 8, 435-446 (2008).

4. Sun, C.-M. et al. Small intestine lamina propria dendritic cells promote de novo generation of Foxp3 T reg cells via retinoic acid. J. Exp. Med. 204, 1775-1785 (2007).

5. Eltzschig, H.K. \& Carmeliet, P. Hypoxia and inflammation. N. Engl. J. Med. 364, 656-665 (2011)

6. Campbell, E.L. et al. Transmigrating neutrophils shape the mucosal microenvironment through localized oxygen depletion to influence resolution of inflammation. Immunity 40, 66-77 (2014).

7. Semenza, G.L. et al. Structural and functional analysis of hypoxia-inducible factor 1. Kidney Int. 51, 553-555 (1997).

8. Karhausen, J. et al. Epithelial hypoxia-inducible factor-1 is protective in murine experimental colitis. J. Clin. Invest. 114, 1098-1106 (2004).

9. Xue, X., Ramakrishnan, S.K. \& Shah, Y.M. Activation of HIF-1 $\alpha$ does not increase intestinal tumorigenesis. Am. J. Physiol. Gastrointest. Liver Physiol. 307, G187-G195 (2014).

10. Cummins, E.P. et al. The hydroxylase inhibitor dimethyloxalylglycine is protective in a murine model of colitis. Gastroenterology 134, 156-165 (2008).

11. Frede, S., Berchner-Pfannschmidt, U. \& Fandrey, J. Regulation of hypoxia-inducible factors during inflammation. Methods Enzymol. 435, 405-419 (2007).

12. Clambey, E.T. et al. Hypoxia-inducible factor-1 alpha-dependent induction of FoxP3 drives regulatory T-cell abundance and function during inflammatory hypoxia of the mucosa. Proc. Natl. Acad. Sci. USA 109, E2784-E2793 (2012).

13. Wobben, R. et al. Role of hypoxia inducible factor- $1 \alpha$ for interferon synthesis in mouse dendritic cells. Biol. Chem. 394, 495-505 (2013).

14. Chassaing, B. et al. Fecal lipocalin 2, a sensitive and broadly dynamic non-invasive biomarker for intestinal inflammation. PLoS One 7, e44328 (2012).

15. De Villiers, W.J., Varilek, G.W., de Beer, F.C., Guo, J.T. \& Kindy, M.S. Increased serum amyloid a levels reflect colitis severity and precede amyloid formation in IL-2 knockout mice. Cytokine 12, 1337-1347 (2000).

16. Westendorf, A.M., Fleissner, D., Hansen, W. \& Buer, J. T cells, dendritic cells and epithelial cells in intestinal homeostasis. Int. J. Med. Microbiol. 300, 11-18 (2010)
17. Rimoldi, M. et al. Intestinal immune homeostasis is regulated by the crosstalk between epithelial cells and dendritic cells. Nat. Immunol. 6, 507-514 (2005).

18. Rescigno, M. \& Di Sabatino, A. Dendritic cells in intestinal homeostasis and disease. J. Clin. Invest. 119, 2441-2450 (2009).

19. Iwata, M. et al. Retinoic acid imprints gut-homing specificity on T cells. Immunity 21, 527-538 (2004).

20. Blomhoff, R. \& Blomhoff, H.K. Overview of retinoid metabolism and function. J. Neurobiol. 66, 606-630 (2006).

21. Coombes, J.L. et al. A functionally specialized population of mucosal CD103 + DCs induces Foxp3 + regulatory T cells via a TGF-beta and retinoic acid-dependent mechanism. J. Exp. Med. 204, 1757-1764 (2007).

22. Hori, S., Nomura, T. \& Sakaguchi, S. Control of regulatory T cell development by the transcription factor Foxp3. Science 299, 1057-1061 (2003).

23. Mittrücker, H.W. \& Kaufmann, S.H.E. Mini-review: regulatory $T$ cells and infection: suppression revisited. Eur. J. Immunol. 34, 306-312 (2004)

24. Rescigno, M. et al. Dendritic cells express tight junction proteins and penetrate gut epithelial monolayers to sample bacteria. Nat. Immunol. 2 , 361-367 (2001).

25. Dorofeyev, A.E., Vasilenko, I.V., Rassokhina, O.A. \& Kondratiuk, R.B. Mucosal barrier in ulcerative colitis and Crohn's disease. Gastroenterol. Res. Pract. 2013, 431231 (2013).

26. Cramer, T. et al. HIF-1alpha is essential for myeloid cell-mediated inflammation. Cell 112, 645-657 (2003).

27. Walmsley, S.R. et al. Hypoxia-induced neutrophil survival is mediated by HIF-1alpha-dependent NF-kappaB activity. J. Exp. Med. 201, 105-115 (2005).

28. Dang, E.V. et al. Control of $T(H) 17 / T(r e g)$ balance by hypoxia-inducible factor 1. Cell 146, 772-784 (2011).

29. Bosco, M.C. et al. Monocytes and dendritic cells in a hypoxic environment: spotlights on chemotaxis and migration. Immunobiology 213, 733-749 (2008).

30. Köhler, T., Reizis, B., Johnson, R.S., Weighardt, H. \& Förster, I. Influence of hypoxia-inducible factor $1 \alpha$ on dendritic cell differentiation and migration. Eur. J. Immunol. 42, 1226-1236 (2012).

31. Naldini, A. et al. Hypoxia affects dendritic cell survival: role of the hypoxiainducible factor- $1 \alpha$ and lipopolysaccharide. J. Cell. Physiol. 227, 587-595 (2012).

32. Taylor, C.T. \& Colgan, S.P. Hypoxia and gastrointestinal disease. J. Mol. Med. (Berl) 85, 1295-1300 (2007).

33. Robinson, A. et al. Mucosal protection by hypoxia-inducible factor prolyl hydroxylase inhibition. Gastroenterology 134, 145-155 (2008).

34. Higashiyama, M. et al. HIF-1 in Tcells ameliorated dextran sodium sulfateinduced murine colitis. J. Leukoc. Biol. 91, 901-909 (2012).

35. Niess, J.H. Role of mucosal dendritic cells in inflammatory bowel disease. World J. Gastroenterol. 14, 5138 (2008).

36. Berger, T. et al. Lipocalin 2-deficient mice exhibit increased sensitivity to Escherichia coli infection but not to ischemia-reperfusion injury. Proc. Natl. Acad. Sci. USA 103, 1834-1839 (2006).

37. Yamamoto, M., Yoshizaki, K., Kishimoto, T. \& Ito, H. IL-6 is required for the development of Th1 cell-mediated murine colitis. J. Immunol. 164, 48784882 (2000).

38. Yen, D. et al. IL-23 is essential for T cell-mediated colitis and promotes inflammation via IL-17 and IL-6. J. Clin. Invest. 116, 1310-1316 (2006).

39. Dominitzki, S. et al. Cutting Edge: trans-signaling via the soluble IL-6R abrogates the induction of FoxP3 in naive CD4 + CD25 T cells. J. Immunol. 179, 2041-2045 (2007).

40. Becker, C. et al. Constitutive $\mathrm{p} 40$ promoter activation and IL-23 production in the terminal ileum mediated by dendritic cells. J. Clin. Invest. 112, 693706 (2003)

41. Katakura, K. et al. Toll-like receptor 9-induced type I IFN protects mice from experimental colitis. J. Clin. Invest. 115, 695-702 (2005).

42. Sainathan, S.K. et al. Toll-like receptor-7 ligand Imiquimod induces type I interferon and antimicrobial peptides to ameliorate dextran sodium sulfateinduced acute colitis. Inflamm. Bowel Dis. 18, 955-967 (2012).

43. Izcue, A., Coombes, J.L. \& Powrie, F. Regulatory Tcells suppress systemic and mucosal immune activation to control intestinal inflammation. Immunol. Rev. 212, 256-271 (2006). 
44. Mucida, D. et al. Reciprocal TH17 and regulatory T cell differentiation mediated by retinoic acid. Science 317, 256-260 (2007).

45. Kühn, R., Löhler, J., Rennick, D., Rajewsky, K. \& Müller, W. Interleukin-10deficient mice develop chronic enterocolitis. Cell 75, $263-274$ (1993).

46. Cai, Z., Luo, W., Zhan, H. \& Semenza, G.L. Hypoxia-inducible factor 1 is required for remote ischemic preconditioning of the heart. Proc. Natl. Acad. Sci. USA 110, 17462-17467 (2013).

47. Hams, E. et al. The hydroxylase inhibitor dimethyloxallyl glycine attenuates endotoxic shock via alternative activation of macrophages and IL-10 production by B1 cells. Shock 36, 295-302 (2011).

48. Johansson-Lindbom, B. et al. Functional specialization of gut CD103 + dendritic cells in the regulation of tissue-selective Tcell homing. J. Exp. Med. 202, 1063-1073 (2005).

49. Jang, Y. et al. UVB induces HIF-1 $\alpha$-dependent TSLP expression via the JNK and ERK pathways. J. Invest. Dermatol. 133, 2601-2608 (2013).

50. Van der Sluis, M. et al. Muc2-deficient mice spontaneously develop colitis, indicating that MUC2 is critical for colonic protection. Gastroenterology 131, 117-129 (2006).

51. Yokoigawa, N. et al. Enhanced production of interleukin 6 in peripheral blood monocytes stimulated with mucins secreted into the bloodstream. Clin. Cancer Res. 11, 6127-6132 (2005).

52. Enss, M.L. et al. Proinflammatory cytokines trigger MUC gene expression and mucin release in the intestinal cancer cell line LS180. Inflamm. Res. 49, 162-169 (2000).
53. Shekels, L.L. \& Ho, S.B. Characterization of the mouse Muc3 membrane bound intestinal mucin 5' coding and promoter regions: regulation by inflammatory cytokines. Biochim. Biophys. Acta 1627, 90100 (2003).

54. Wallace, J.L., Vong, L., Dharmani, P., Srivastava, V. \& Chadee, K. Muc-2deficient mice display a sex-specific, COX-2-related impairment of gastric mucosal repair. Am. J. Pathol. 178, 1126-1133 (2011).

55. Ho, S.B. et al. Cysteine-rich domains of muc3 intestinal mucin promote cell migration, inhibit apoptosis, and accelerate wound healing. Gastroenterology 131, 1501-1517 (2006).

56. Cummins, E.P., Doherty, G.A. \& Taylor, C.T. Hydroxylases as therapeutic targets in inflammatory bowel disease. Lab. Invest. 93, 378-383 (2013).

57. Colgan, S.P. \& Taylor, C.T. Hypoxia: an alarm signal during intestinal inflammation. Nat. Rev. Gastroenterol. Hepatol. 7, 281-287 (2010).

58. Okayasu, I. et al. A novel method in the induction of reliable experimental acute and chronic ulcerative colitis in mice. Gastroenterology 98, 694-702 (1990).

59. Weischenfeldt, J. \& Porse, B. Bone marrow-derived macrophages (BMM): isolation and applications. CSH Protoc 2008: pdb.prot5080 (2008).

60. Tambuwala, M.M. et al. Loss of prolyl hydroxylase-1 protects against colitis through reduced epithelial cell apoptosis and increased barrier function. Gastroenterology 139, 2093-2101 (2010). 